\title{
A study on debris flow disasters along Japanese railways and its critical rainfalls
}

\author{
S. Watanabe ${ }^{1}$, T. Sugiyama ${ }^{1}$, O. Nunokawa ${ }^{1}$, T. Fujii ${ }^{1}$, K. Okada ${ }^{2}$ \\ \& H. Mitsunaka ${ }^{3}$ \\ ${ }^{I}$ Railway Technical Research Institute, Tokyo, Japan \\ ${ }^{2}$ Kokushikan University, Tokyo, Japan \\ ${ }^{3}$ Shikoku Japan Railway, Kagawa, Japan
}

\begin{abstract}
In the year 2004 in Japan, a huge number of disasters occurred due to heavy rainfalls during annual rainy seasons, and typhoons hit in Japan more than ever. An area on the Yosan line in Shikoku Japan Railway suffered especially from serious slope failures after being hit four times by Typhoons. In this paper, we introduce an example of the debris flow that took place in the area; and clarify the causes of such disasters in view of the geological and geographical features of the area. It also shows that an evaluation of the critical rainfalls, which caused debris flow with an analysis of rainfalls observed at that time.

Keywords: debris flow, maximum hourly rainfall, continuous rainfall, critical rainfall.
\end{abstract}

\section{Introduction}

In Japan, most railways suffered from severe natural environments such as heavy rainfalls due to typhoons and annual rainy season causing slope failures. In order to secure safe train operations during such heavy rainfalls, the railways have imposed strict operational restrictions to prevent presumable accidents. Despite a large number of natural disasters occurred in the past, grave accidents i.e. derailments and vehicle overturning have scarcely occurred by appropriate operational restrictions.

In the year of 2004 in Japan, heavy rainfalls due to annual rainy season and typhoons caused a huge number of disasters. Especially, the area on Yosan line under jurisdiction of Shikoku Japan Railway Company suffered from serious slope failures four times due to Typhoons. 
In this paper, we have introduced a typical example of the debris flow that took place in the area, and clarified the causes of such disasters in view of geological and geographical features of the area. We have also shown the relationship between the critical rainfalls and debris flow with an analysis of rainfalls observed at that time of disaster.

\section{Suffering area}

\subsection{Disaster occurrence date and suffering area}

On the area on Yosan line in Shikoku, slope failures, embankment failures, and other natural disasters occurred due to heavy rainfall during typhoons. The total number of disasters reached 23; most of them occurred between Sekikawa and Takihama stations. Table 1 shows the details of three typical incidents due to debris flow, which especially damaged Yosan line.

Table 1: $\quad$ Suffered points, occasion date, and classification.

\begin{tabular}{c|c|c}
\hline Sufferring point & Occasion date & Classification \\
\hline \hline $93020 \mathrm{~m}$ & $2004 / 08 / 18$ & Sediment inflow by debris flow \\
\hline $93020 \mathrm{~m}$ & $2004 / 10 / 21$ & Sediment inflow by debris flow \\
\hline $96350 \mathrm{~m}$ & $2004 / 08 / 18$ & $\begin{array}{c}\text { Sediment inflow by debris flow and } \\
\text { embankment failure }\end{array}$ \\
\hline $96620 \mathrm{~m}$ & $2004 / 08 / 18$ & Sediment inflow by debris flow \\
\hline
\end{tabular}

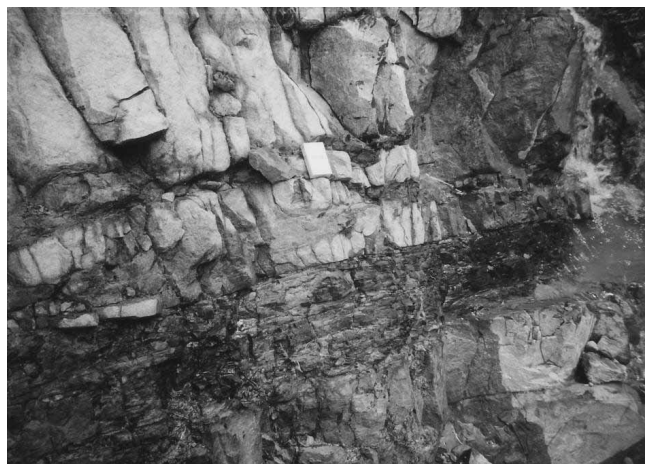

Figure 1: $\quad$ Bedrock of concerned area.

\subsection{Topography and geological feature of disaster area}

This area is a mountainous region and the edge of natural slope of valley. The geological timescale of this region is Mesozoic era, compounding with sandstone and shale as shown in Figure 1. Therefore, foundation of bedrock of the region tends to be fragment. Cohesive soils around this area are made by these fragment, and depositing on firm bedrock as shown in Figure 2. The deposits are 
unstable and tend to collapse easily on a boundary of the deposits and bedrock. The deposits include weathered rocks, which collapsed from bedrock has covered the bottom of the mountain stream. Therefore, this area is likely in danger of debris flow where heavy rainfall anticipated.

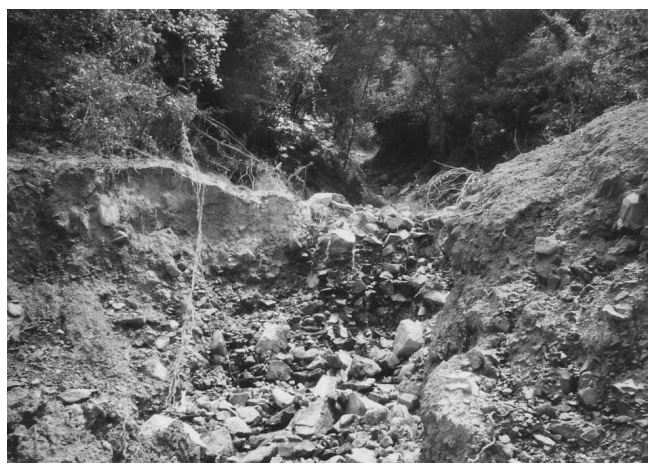

Figure 2: $\quad$ Sediments on mountain stream.

\section{Outline of disasters and restoration method}

\subsection{A view of provision for restoration}

As discussed previously, this area is apprehensive for debris flow. However, it is difficult to protect railways completely from disasters due to debris flow. Therefore, it is practical and economical to take countermeasures such as structural restoration and operational restoration for reducing the damage to the railway after the debris flow occurs. As a measure for structural restoration, it is effective to make a sediment control dam on the mountain stream, which has a possibility to cause a debris flow. In addition, it is preferable to dredge sediments behind the dam regularly to maintain a function of the sediment control dam.

As operational restoration, it is preferable to detect occurrence of debris flow and to suspend train operations immediately. In order to reduce damage caused by recurrence of debris flow, it is preferable to implement strict operational restrictions.

\subsection{Outline of disasters and restoration method around $93020 \mathrm{~m}$}

\subsubsection{Outline of disasters caused by typhoon No.15 and No.21 Case of Typhoon No.15}

Figure 3 shows a schematic map of this area with the location of slope failure caused by the Typhoon No. 21. This area lies to the north slope of a portal of Kitayama tunnel. There is a sediment control dam in the place on the upper reaches from a cut slope along the railway $50 \mathrm{~m}$. Figure 4 shows the situation of sediment load right after disaster. 


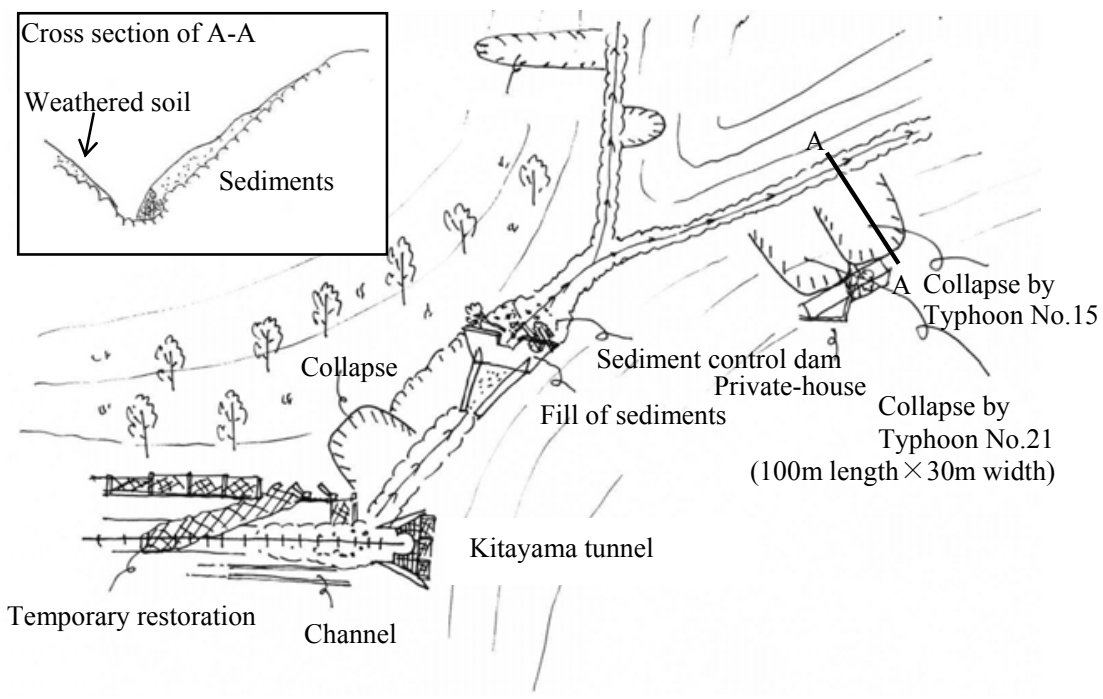

Figure 3: $\quad$ Schematic map around $93020 \mathrm{~m}$.

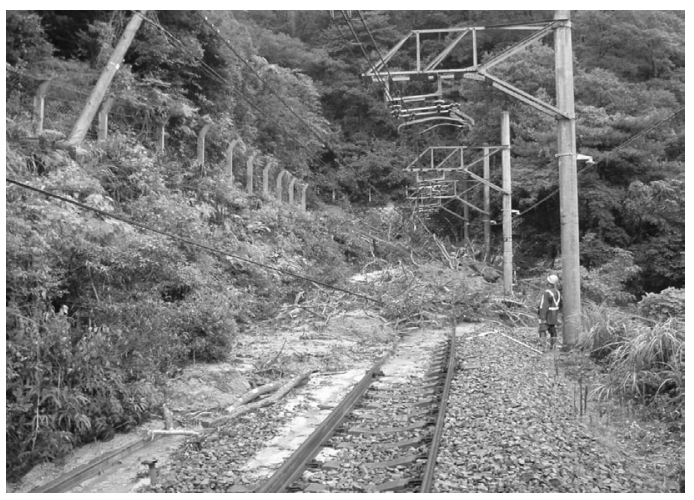

Figure 4: $\quad$ Situation of sediment load.

The origin of this debris flow is sediments of slope failure, which occurred at the top of mountain at the location of upper reaches from the railway $150 \mathrm{~m}$. It is presumable that the sediment dammed up the mountain stream shortly, and flowed down at a burst. After the debris flow, there were still unstable sediments remained on the slope. Therefore, small rainfall would trigger another debris flow.

\section{Case of Typhoon No.21}

A side slope of previous origin collapsed and flowed out the temporary restoration. 


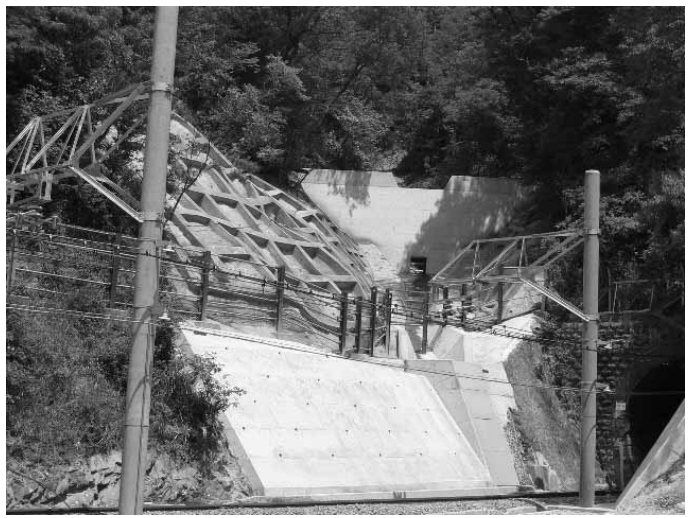

Figure 5: $\quad$ Restoration method around $93020 \mathrm{~m}$.

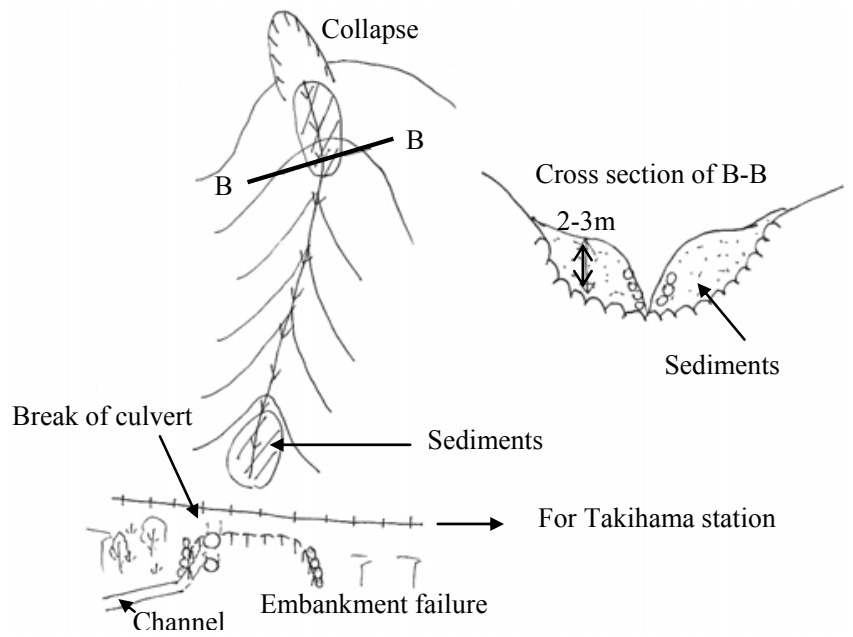

Figure 6: $\quad$ Schematic map around $93350 \mathrm{~m}$.

\subsubsection{A restoration method}

As a structural restoration, the height of an actual sediment control dam extended for $1.5 \mathrm{~m}$ from original one, and two new sediment control dams were provided. Then spray concrete and concrete frame were constructed on the cut slope alongside the railway to prevent slope failure as shown in Figure 5.

In addition, detectors were installed to monitor possible rock falling.

\subsection{Outline of disasters and restoration method around $96350 \mathrm{~m}$}

\subsubsection{Outline of disasters}

Figure 6 shows the schematic map of this area and Figure 7 shows a situation of mountain stream right after disaster. In this area, embankment failures were also 
evident due to stoppage of culvert under the embankment by sediments of debris flow.

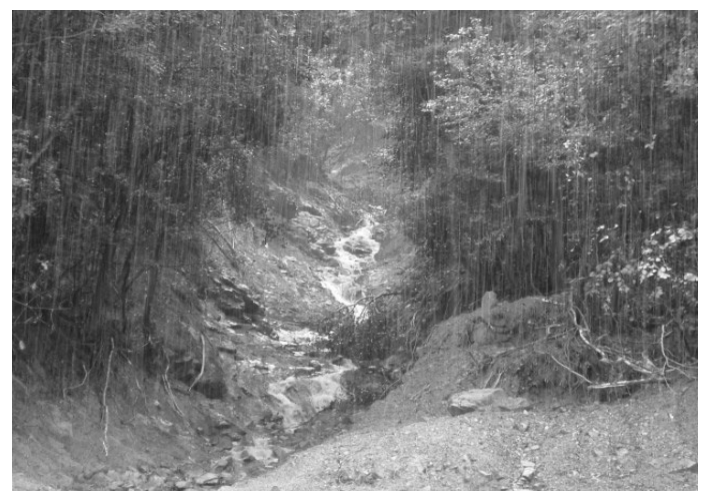

Figure 7: Situation of mountain stream.

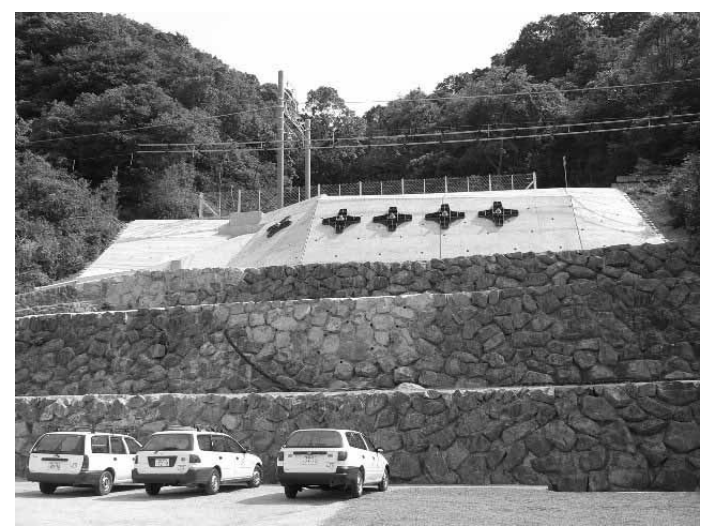

Figure 8: $\quad$ Restoration method around $96350 \mathrm{~m}$.

A distance of the mountain stream was approximately $300 \mathrm{~m}$, and a slope of the streambed was gradual. It is presumable that sediments and rainwater flowed down eroding deposits of the streambed.

\subsubsection{A restoration method}

As a structural restoration, a retaining wall and a sand filtration fence were provided as a countermeasure of sediment inflow alongside the railways. In addition, the embankment was reconstructed with concrete panels and five ground-anchors, in which estimated sliding mode is taken into consideration. Figure 8 shows the schematics of the total restoration. 


\subsection{Outline of disasters and restoration method around $96620 \mathrm{~m}$}

\subsubsection{Outline of disasters}

The lower part of the mountain stream is of thick sediments area as shown in Figure 9, and a trace of erosion due to debris flow was confirmed. It is assumable that rainwater involving loose sediments flowed down gradually, and it became a huge flow eroding sediments on the streambed.

\subsubsection{A restoration method}

A new sand filtration fence was provided to preventing sediments discharge on the top of the actual sediment control dam as shown in Figure 10. A rock-fall detector was also provided as an operational restoration.

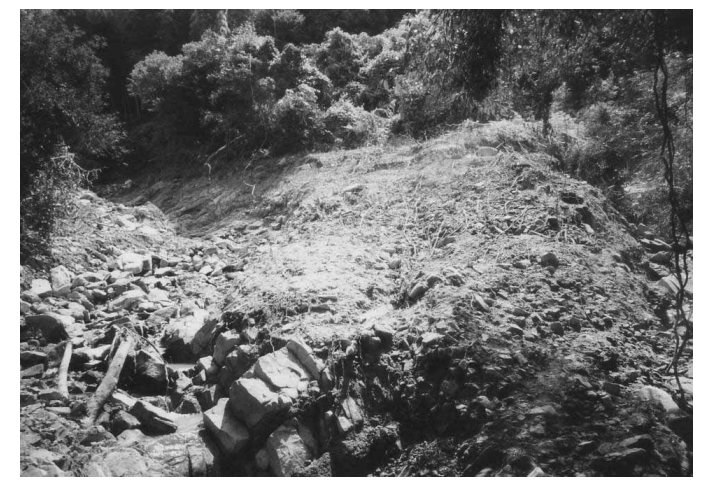

Figure 9: Thick sediments on lower part of mountain stream.

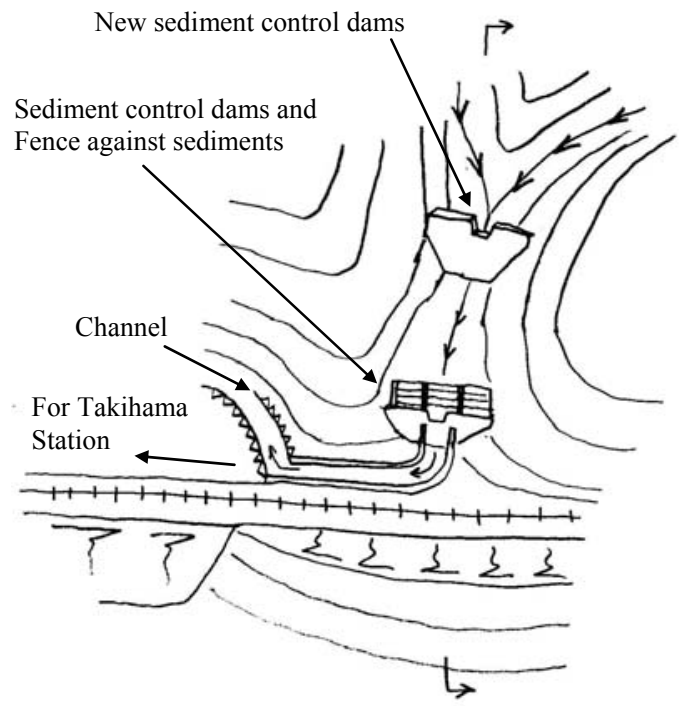

Figure 10: Schematic figure of restoration method around $96620 \mathrm{~m}$. 


\section{An analysis of rainfall index and critical rainfall}

The hourly rainfall record at the occurring time of the debris flow due to typhoon No.15 and No. 21 are shown in Figure 11 and Figure 12 respectively. In case of the typhoon No. 15, the rain continued intermittently for one day, and the failure occurred when continuous rainfall of $205 \mathrm{~mm}$. The maximum hourly rainfall was $55 \mathrm{~mm} / \mathrm{h}$. Similarly, the continuous rainfall was $308 \mathrm{~mm}$ and the maximum hourly rainfall was $58 \mathrm{~mm} / \mathrm{h}$ due to typhoon No. 21. Table 2 shows the amount of rainfall indices.

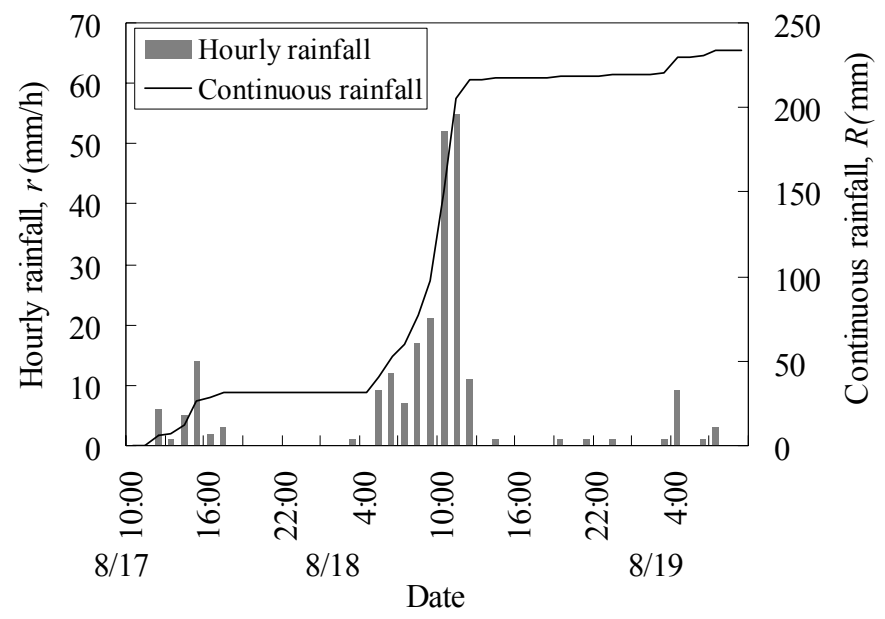

Figure 11: Hourly rainfall record caused by Typhoon No.15.

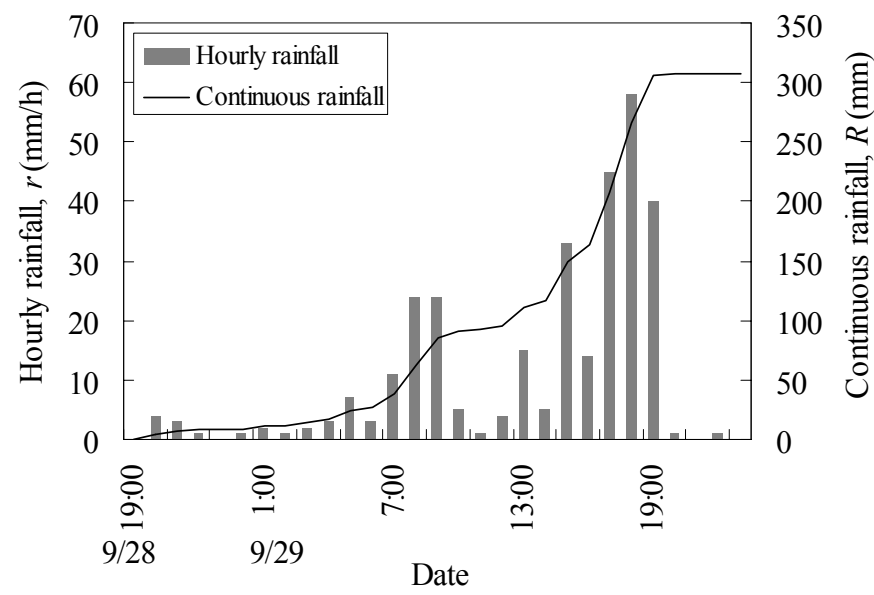

Figure 12: Hourly rainfall record caused by Typhoon No.21. 
Table 2: $\quad$ Maximum amount of rainfall indices.

\begin{tabular}{c|c|c}
\hline Typhoon & Maximum hourly rainfall $(\mathrm{mm} / \mathrm{h})$ & Continuous rainfall $(\mathrm{mm})$ \\
\hline \hline No.15 & 55 & 205 \\
\hline No.21 & 58 & 308 \\
\hline
\end{tabular}

Figure 13 and Figure 14 show the maximum hourly rainfalls and maximum continuous rainfalls of each year from 1977 to 2004 respectively. By processing these data with Gumbel method, we found that the return period of 55 and 58 $\mathrm{mm}$ of the maximum hourly rainfalls are 30 years, and that of 208 and $308 \mathrm{~mm}$ of the continuous rainfalls are 4 to 5 years. These figures have also indicated the years of debris flow occurred.

It is apparent from Figure 13 and Figure 14 that the amount of the maximum hourly rainfall does not necessarily related to the occurrence of the debris flow. Similarly, there are several cases that the continuous rainfall exceeds the amount of that due to typhoon No.15 and No. 21, however no debris flow substantially occurred. These facts indicate that a combined index reflecting both of the maximum hourly rainfall and the amount of the continuous rainfall required in order to predict precisely the occurrence of debris flow.

Figure 15 shows the relationship between hourly maximum rainfall and continuous rainfall observed from 1976 to 2003, including typhoon No.15 and No. 21 cases. The solid line in the figure indicates the records in 1987, 1989 and 2004, in which disasters due to debris flow occurred. It is highly likely that debris flow would occur from this figure in cases of continuous rainfalls exceeding $200 \mathrm{~mm}$ and maximum hourly rainfall is beyond $30 \mathrm{~mm} / \mathrm{h}$. It is also likely that a long duration of rainfall followed by a huge amount of rain would cause disasters due to debris flow.

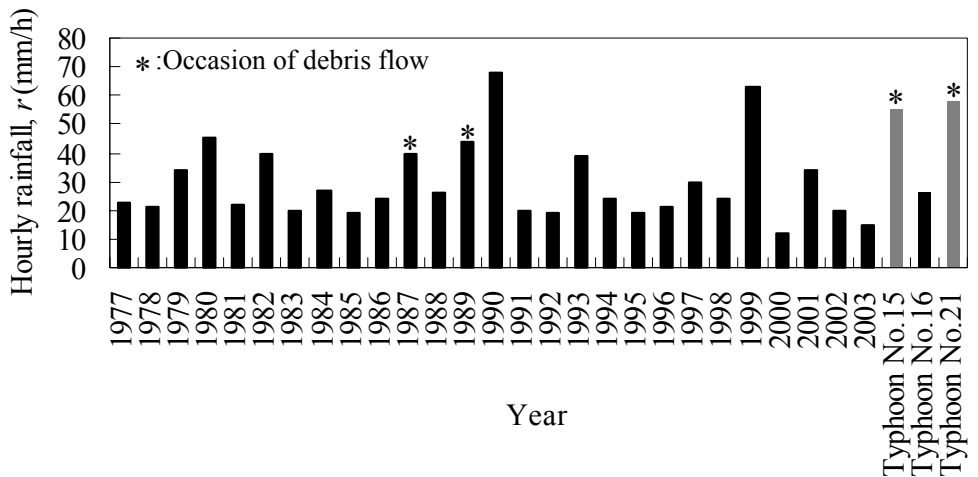

Figure 13: Maximum hourly rainfall record for each year from 1977 to 2004 . 


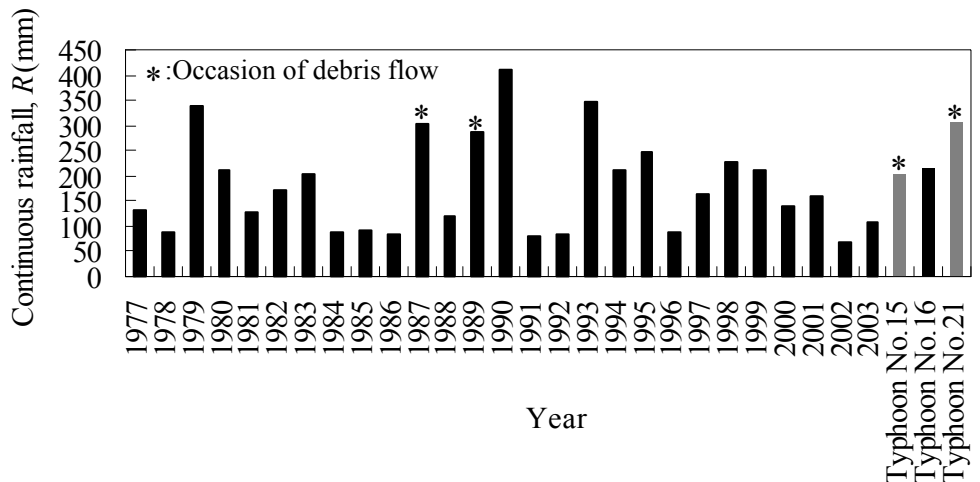

Figure 14: Maximum continuous rainfall record for each year from 1977 to 2004.

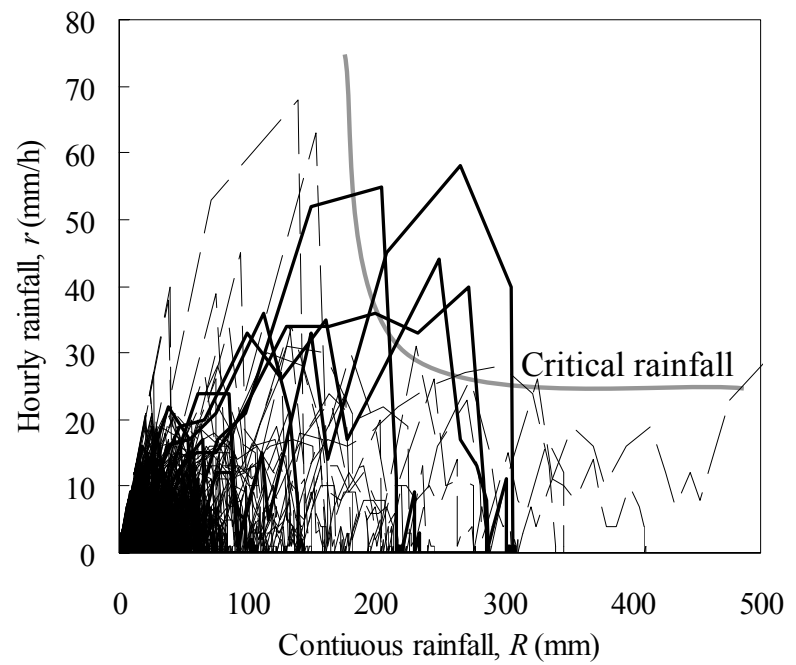

Figure 15: The measured rainfall indices from 1977 to 2004.

\section{Concluding remarks}

The conclusions of this paper are as follows:

1) As a restoration method, it is difficult and uneconomical to prevent entirely the intrusion of all the debris flow into railway tracks. It is hence important to provide sediment control dams, and to secure safe train operations by implementing precise train controls based on the intensity of precipitation.

2) The analysis of rainfall, which caused the debris flow in the area, shows a high probability of debris flow when the hourly rainfall intensity reaches $30 \mathrm{~mm} / \mathrm{h}$, and the continuous precipitation reaches $200 \mathrm{~mm}$. 